\title{
Production and Utilization of Extracellular Matrix Components by Human Melanocytes
}

\author{
BRIAN K. McCLENIC, RAJ S. MITRA, BRUCE L. RISER, \\ BRIAN J. NICKOLOFF, VISHVA M. DIXIT, and JAMES VARANI ${ }^{1}$ \\ Department of Pathology, University of Michigan Medical School, Ann Arbor, Michigan 48109
}

\begin{abstract}
Normal human melanocytes were separated from keratinocytes and maintained in culture using KGM medium supplemented with 12-O-tetradecanoylphorbol acetate and cholera toxin. The melanocytes were examined for the production of extracellular matrix molecules including fibronectin, laminin, and thrombospondin and for the utilization of these molecules in adhesion and motility assays. Melanocytes produced significant amounts of fibronectin as indicated by biosynthetic labeling/immunoprecipitation and by enzyme-linked immunosorbent assay (ELISA). Fibronectin was expressed on the surface of these cells. Laminin was also produced by melanocytes and expressed on the cell surface. The amount of laminin produced was significantly less than the amount of fibronectin. In contrast, melanocytes did not produce measurable thrombospondin as indicated by biosynthetic labeling/immunoprecipitation. Only traces of thrombospondin were detected by ELISA and no surface fluorescence was observed. When examined in adhesion and motility assays, melanocytes were found to utilize fibronectin for both processes. Laminin also stimulated adhesion but it was much less effective than fibronectin. Thrombospondin did not stimulate either attachment and spreading or motility. The pattern of extracellular matrix molecule production and utilization by melanocytes is significantly different from that shown previously for human epidermal keratinocytes ( $J$. Varani et al., 1988, J. Clin. Invest. 81, 1537). These differences may underlie the differences with which the two cell types interact with basement membranes in vivo. (c) 1989 Academic Press, Inc.
\end{abstract}

Previous studies in our laboratory have shown that thrombospondin is a major extracellular matrix protein produced by normal keratinocytes as well as by various squamous carcinoma cells [1-3]. Thrombospondin serves as an adhcsion factor for normal keratinocytes and squamous carcinoma cells and our data suggest that it is more effective at promoting attachment and spreading than either fibronectin or laminin [1, 4]. In vivo, thrombospondin is localized to the dermal-epidermal junction and the basement membrane zone around sweat glands [5]. Both are sites at which actively prolifcrating kcratinocytes are in contact with the basement membrane.

Melanocytes comprise a second important integumentary cell population. There is approximately one melanocyte for every $10-15$ keratinocytes [6]. While melanocytes are closely associated with basal keratinocytes, they do not form desmosomes with neighboring cclls. At the basal surface of melanocytes, which is in close apposition to the basement membrane, structures resembling the hemidesmosomes of keratinocytes can be seen. Anchoring filaments extend from the

\footnotetext{
1 To whom reprint requests should be addressed.
} 


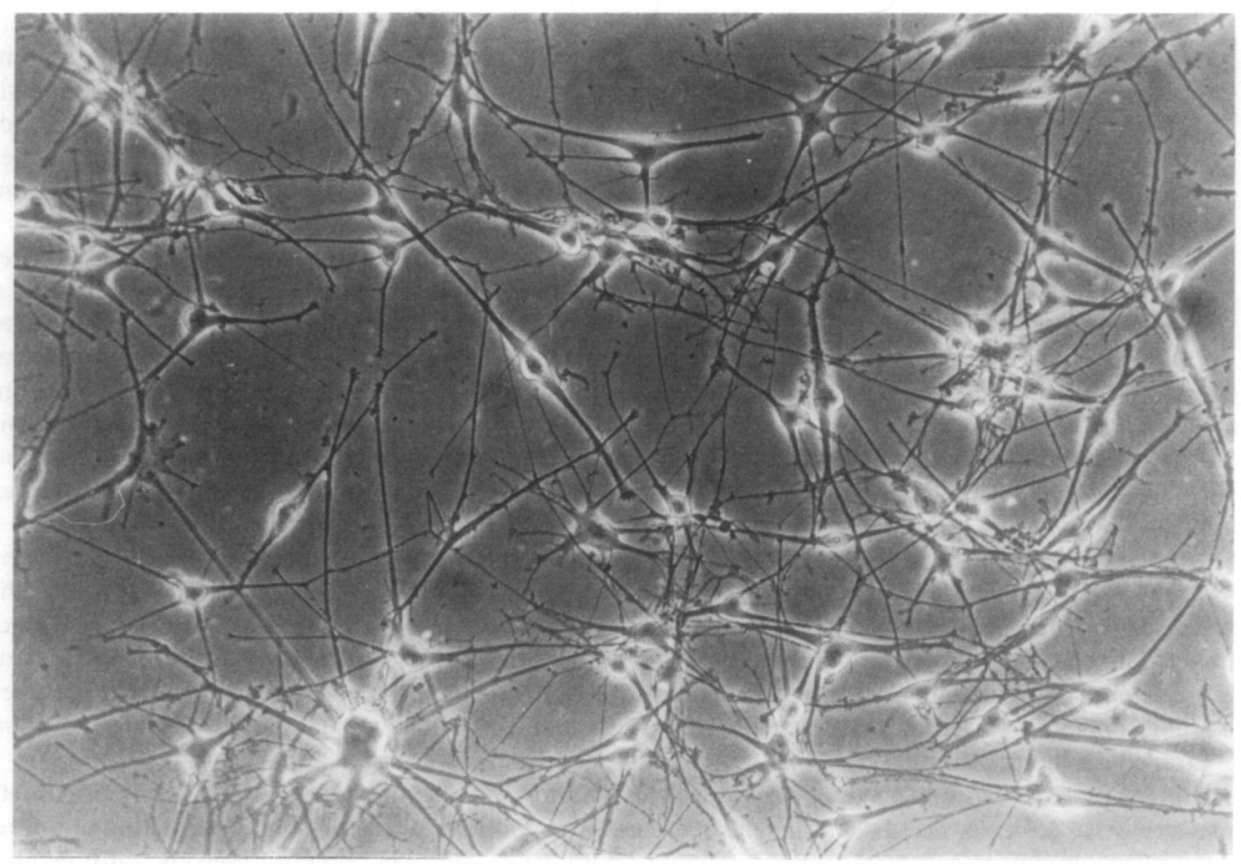

Fig. 1. Phase-contrast photomicrography of normal human melanocytes in culture $(225 \times)$.

plasma membrane to the basement membrane. However, there is no sub-basal dense (adhesion) plaque as is found in basal keratinocytes [7]. Furthermore, melanocytes can sometimes beound in a supra-basilar position [8]. The biochemical basis for the differences between keratinocytes and melanocytes in their interaction with the underlying basement membrane is not known. The present study examines the production of extracellular matrix molecules by human skin melanocytes and the influence of these molecules on melanocyte biological properties (i.e., cell-substrate adhesion and motility). The results obtained in the present study are compared to the results of similar studies with epidermal keratinocytes and squamous carcinoma cells [1-4] and similar studies with malignant melanoma cells $[3,4]$.

\section{MATERIAL AND METHODS}

Cell culture. Normal melanocytes were established in culture from neonatal foreskins. Tissue processing and establishment of melanocyte cultures was done using methods previously described by Eisinger and Marko [9]. The melanocytes were seeded into 35-mm plastic culture dishes and grown in keratinocyte growth media (KGM) (modified MCDB 153, Clonetics Corp. San Diego, CA) supplemented with $10 \mathrm{nM}$ cholera toxin and $10 \mathrm{ng} / \mathrm{ml} 12-\mathrm{O}$-tetradecanoylphorbol 13 -acetate (TPA). The cells were grown at $37^{\circ} \mathrm{C}$ and $5 \% \mathrm{CO}_{2}$. This combination of reagents has been shown previously to suppress keratinocyte proliferation while supporting the growth of melanocytes [9]. Under these conditions, most of the cells contained a centrally located nucleus surrounded by a small amount of cytoplasm and two or more long dendritic processes. Occasional large, flat, melanin-containing cells were also seen. This morphological picture is consistent with the previously published description [9]. The morphological appearance of the cultures is shown in Fig. 1. 


\section{McClenic et al.}

Reagents. Thrombospondin was purified from the supernatant fluid of thrombin-activated platelets as described [10]. The purified thrombospondin migrated as a single protein band with an apparent mol wt of $180 \mathrm{kDa}$ when examined by sodium dodecyl sulfate-polyacrylamide gel electrophoresis (SDS-PAGE) under reducing conditions. The production and characterization of polyclonal antibodies directed against thrombospondin have been described previously [1, 11-13]. Polyclonal antibodies to thrombospondin reacted with thrombospondin (undiluted to $10^{5}$ dilution) in enzymc-linked immunosorbent assay (ELISA) but did not react with fibronectin or laminin.

Laminin was prepared from the Englebreth-Holm-Swarm (EHS) tumor by the method of Timpl $e t$ al. [14]. Purity of the laminin was assessed by SDS-PAGE and by ELISA [15]. When examined on a $7 \%$ SDS-polyacrylamide gel under reducing conditions, only two protein bands (at 200 and $400 \mathrm{kDa}$ ) were seen. The laminin reacted by ELISA with monospecific polyclonal anti-laminin antibodies at dilutions up to $1: 10^{6}$ but did not react with polyclonal antibodies to thrombospondin or fibronectin. Rabbit polyclonal anti-laminin serum was prepared by repeated intradermal injection of murine laminin into New Zealand white rabbits. The anti-laminin serum reacted with laminin by immunoblotting and by ELISA (undilute to $10^{6}$ dilution) but did not react with thrombospondin or with human plasma fibronectin.

Human plasma fibronectin was obtained from Collaborative Research (Boston, MA). Analysis by SDS-PAGE under reducing conditions showed a single band with an apparent mol wt of $200 \mathrm{kDa}$. The fibronectin reacted with anti-fibronectin antibodies (undiluted to $10^{6}$ dilution) in FIISA bil did tot react with anti-laminin or anti-thrombospondin antibodies. Rabbit polyclonal anti-fibronectin was purchased from Accurate Scientific and Chemical Co. (Westbury, NY). The anti-fibronectin reacted with fibronectin by ELISA (undilute to $10^{6}$ dilution) but did not react with laminin or thrombosponitin.

Transforming growth factor- $\beta$ (TGF- $\beta$ ) was obtained from Collaborative Research.

Biosynthetic labeling. The cells were grown in $60-\mathrm{mm}$ (diameter) culture dishes to an approximate density of $1 \times 10^{6}$ cells per dish. The cells were washed and incubated for 30 min in methionine-free, serun-[ree minimum essential medium (Flow Laboratories, McLean, VA) followed by a 4-h incubation in the same medium supplemented with $100 \mu \mathrm{C}$ per dish of $\left[{ }^{35} \mathrm{~S}\right]$ methionine $(1000-1400 \mu \mathrm{C} / \mu \mathrm{mol}$; NEN, Boston, MA). The 4-h cells were lysed in a solution of phosphate-buffered saline (PBS) containing three detergents (1\% Triton X-100, 0.5\% sodium deoxycholate, and $0.1 \%$ SDS; all obtained from Sigma Chemical Co., St. Louis, MO) and protease inhibitors including $20 \mathrm{mM}$ EDTA, 5 $\mathrm{m} M N$-ethylmaleimide, $2 \mathrm{~m} M$ phenylmethylsulfonyl fluoride (PMSF) and $10,1 / 10 \mathrm{mi}$ of a protease inhibitor cocktail containing $1 \mathrm{mg} / \mathrm{ml}$ leupeptin, $2 \mathrm{mg} / \mathrm{ml}$ antipain, $10 \mathrm{mg} / \mathrm{ml}$ benzamidine, 10,000 kallikrein-inactivating units $/ \mathrm{ml}$ aprotinin, $1 \mathrm{mg} / \mathrm{ml}$ chymostatin, and $1 \mathrm{mg} / \mathrm{ml}$ pepstatin, as described by Ronnett et al. [16] in studies on the insulin receptor. All of the protease inhibitors were obtained from Sigma Chemical Co. The cell lysates were frozen at $-80^{\circ} \mathrm{C}$, thawed, and clarified by ultracentrifugation $(37,000 \mathrm{~g}$ for $60 \mathrm{~min})$. Immunoreactive fibronection, laminin, and thrombospondin were precipitated with a $1: 100$ dilution of the appropriate rabbit polyclonal antibodies and protein A-Sepharose (Sigma Chemical Co.) according to the protocol of Ruddon et al. [17]. Normal rabbit serum served as a control. The washed immunoprecipitates were divided in half and eluted with bolling ( 5 min) in twofold concentrated Laemmli SDS-PAGE sample buffer [18], either with or without 2\% 2mercaptoethanol. The immunoprecipitated material was fractionated on a $5 \%$ polyacrylamide gel employing the Laemmli system. Radioactive bands were visualized by fuorography with En ${ }^{3} \mathrm{Hance}_{2}$ (NEN), exposing the dried gels to X-ray film (Kodak XAR-2) for 2 days. In addition, a small sample of each immunoprecipitate was analyzed for total $\left[{ }^{35} \mathrm{~S}\right]$ methionine incorporation. The amount of radioactivity present in the immunoprecipitate was compared to the total amouni incorporated into trichloroacetic acid ( $10 \%$ final concentration)-precipitable material to give a quantitative measure of the amounts of each protein biosynthesized.

Enzyme-linked immunosorbent assay (ELISA). ELISAs were performed to quantify the amount of immunoreactivve fibronectin, laminin, or thrombospondin secreted into the culture medium by melanocytes. Briefly, cells grown in culture medium were washed twice in KGM and incubated for 2 $\mathrm{h}$ in KGM. The 2-h culture fluids were harvested and clarified by low-speed centrifugation, and $100 \mu \mathrm{l}$ was added to wells of a 96-well plate (Falcon Plastics, Oxnard, CA) from lots hat been preselected for acceptability in ELISAs. The plate was then incubated for $4 \mathrm{~h}$ at $37^{\circ} \mathrm{C}$. Culture medum served as the control. Purified fibronectin, laminin, and thrombospondin $(0.5-0.00005 \mu \mathrm{g} / \mathrm{ml})$ were also added to the assay plate in KGM to serve as standards. After the 4 -h incubation, the culture medium from the cells and the control culture media were removed from the wells and the ELISA was performed as described previously [15]. The cells from which the culture medium was obtained were harvested with trypsin and counted.

Immunofluorescence. Melanocytes were examined for anti-fibronectin, anti-laminin, and antithrombospondin binding by indirect immunofluorescence. For this, $1.0 \times 10^{5}$ cells were seeded into 


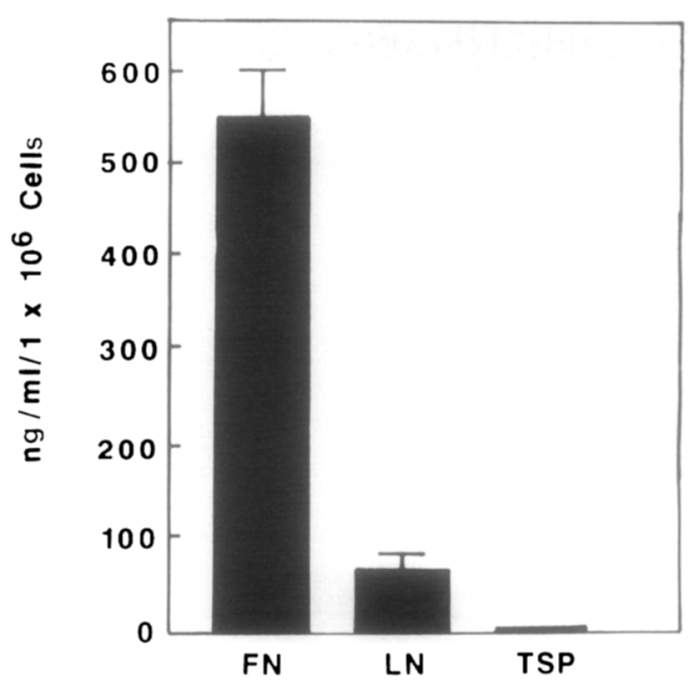

Fig. 2. Production of extracellular matrix molecules by melanocytes as indicated by ELISA. Values represent amounts of fibronectin (FN), laminin (LN), and thrombospondin (TSP) produced in $2 \mathrm{~h} \pm$ standard deviations based on three separate experiments with duplicate samples per experiment.

$20 \times 20-\mathrm{mm}$ glass coverslips and cultured for 1 or 2 days. At the time of staining the culture medium was removed and the cells were gently washed three times in cold PBS. All subsequent steps were carried out at $4^{\circ} \mathrm{C}$. The cells were stained initially with $1: 20$ dilution of anti-fibronectin, anti-laminin, anti-thrombospondin, or normal rabbit serum $(45 \mathrm{~min})$ and then washed three times. They were then stained with a $1: 30$ dilution of fluorescein-conjugated swine anti-rabbit serum ( $45 \mathrm{~min}$ ) obtained from Accurate Scientific and Chemical Co. Following three additional rinses in PBS, the coverslips were placed on glass slides and viewed immediately by standard fluorescence microscopic techniques.

Adhesion assay. Cell attachment and spreading on variously coated wells of a 24 -well plate was used as a measure of cell adhesion. Wells were treated with $25 \mu \mathrm{g}$ of fibronectin, laminin, or thrombospondin in $0.5 \mathrm{ml}$ of $\mathrm{KGM}$ and incubated for $2 \mathrm{~h}$ at $37^{\circ} \mathrm{C}$. Control wells were treated with KGM alone. After the 2-h incubation, wells were emptied of the excess treatment fluid and washed once with KGM. Each well then received $0.5 \mathrm{ml}$ of $\mathrm{KGM}$ supplemented with $1 \% \mathrm{BSA}$. The cells were added 15 min later and incubated at $37^{\circ} \mathrm{C}$. At various times thereafter, the nonattached cells were removed and counted with an electronic particle counter. The wells were then washed and flooded with $2 \%$ glutaraldehyde. The percentage of attached cells which were spread was determined microscopically using a calibrated grid. The data were expressed as the percentage of the initially added cells which were attached and spread at each time point.

Motility assays. Motility was assessed using the agarose explant assay as described previously [19]. The cells were harvested, centrifuged into a pellet, and resuspended at $1 \times 10^{7}$ cells/ml of KGM supplemented with $10 \%$ fetal bovine serum and $0.2 \%$ Seaplaque agarose (Marine Colloids, Rockville, $\mathrm{ME}$ ). Agarose drops of approximately $5 \mu \mathrm{l}$ size were placed in the center of the wells of a 96 -well cell culture dish. After allowing the agarose drops to solidify, the wells were overlayed with $200 \mu$ l of KGM supplemented with $200 \mu \mathrm{g}$ of $\mathrm{BSA} / \mathrm{ml}$ with or without $10 \mu \mathrm{g}$ of fibronectin, laminin, or thrombospondin. Cell migration out of the agarose drops was measured after $18 \mathrm{~h}$.

\section{RESULTS}

Production and surface expression of extracellular matrix molecules by melanocytes. ELISAs were used to examine the production of extracellular matrix molecules by melanocytes. Cells were grown in $35-\mathrm{mm}$ (diameter) culture dishes to approximately $1 \times 10^{5}$ cells per dish. Culture fluids were prepared as described 


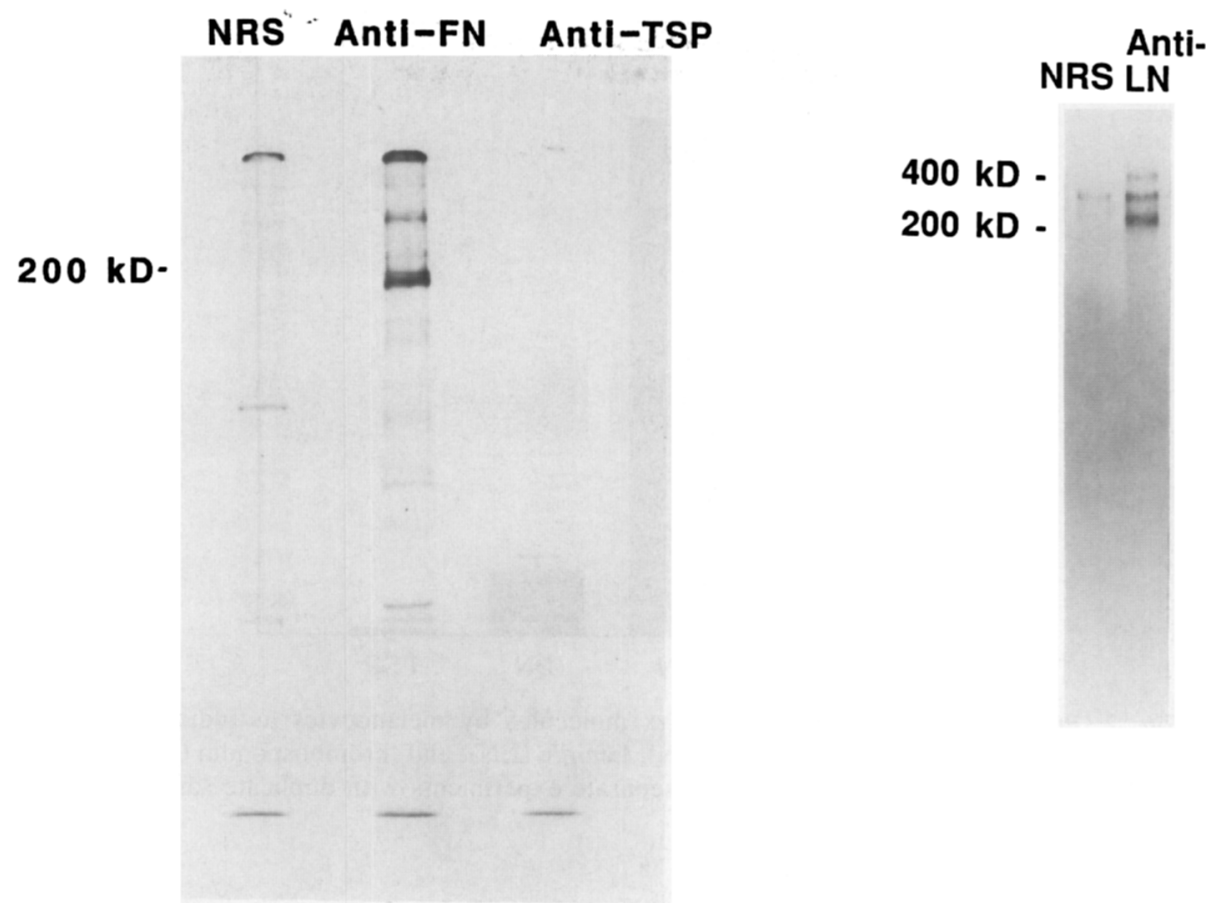

Fig. 3. Analysis of fibronectin, laminin, and thrombospondin biosynthesis by melanocytes. $\mathrm{EX}$ tracts were prepared from cells biosynthetically labeled with $\left[^{35} \mathrm{~S}\right]$ methionine and precipifated with normal rabbit serum (NRS), anti-fibronectin (anti-FN), anti-laminin (anti-LN), or anti-thrombospondin (anti-TSP). The precipitated material was separated by SDS-PAGE under reducing conditions and examined by autoradiography.

under Materials and Methods and examined for immunoreactive fibronectin, laminin, and thrombospondin. Both fibronectin and laminin were detected in the culture fluid of the melanocytes under the conditions of the assay. There was significantly more fibronectin than laminin (Fig. 2). In contrast, immunoreactive thrombospondin was barely detectable under the same conditions (Fig. 2). The lack of thrombospondin production by melanocytes is of interest since our previous studies have shown that normal and malignant keratinocytes produce large amounts of thrombospondin as well as fibronectin and laminin [1-4] and since studies by other investigators have demonstrated thrombospondin production by platelets, fibroblasts, macrophages, other epithelial cells, and endothelial cells $[20-26]$.

Biosynthetic labeling with $\left[{ }^{35} \mathrm{~S}\right]$ methionine followed by imunoprecipitation, SDS-PAGE, and autoradiography was used to identify the molecular forms of fibronectin, thrombospondin, and laminin produced by the cultured melanocytes. The cells were labeled and extracted as described under Materials and Methods and immunoprecipitated with the rabbit polyclonal antibodies to the three matrix proteins. When the immunoprecipitates were separated by SDS-PAGE under reducing conditions and examined by autoradiography, a distinct band at $200 \mathrm{kDa}$ was seen with anti-fibronectin (Fig. 3). In contrast, no detectable immunoprecipi- 

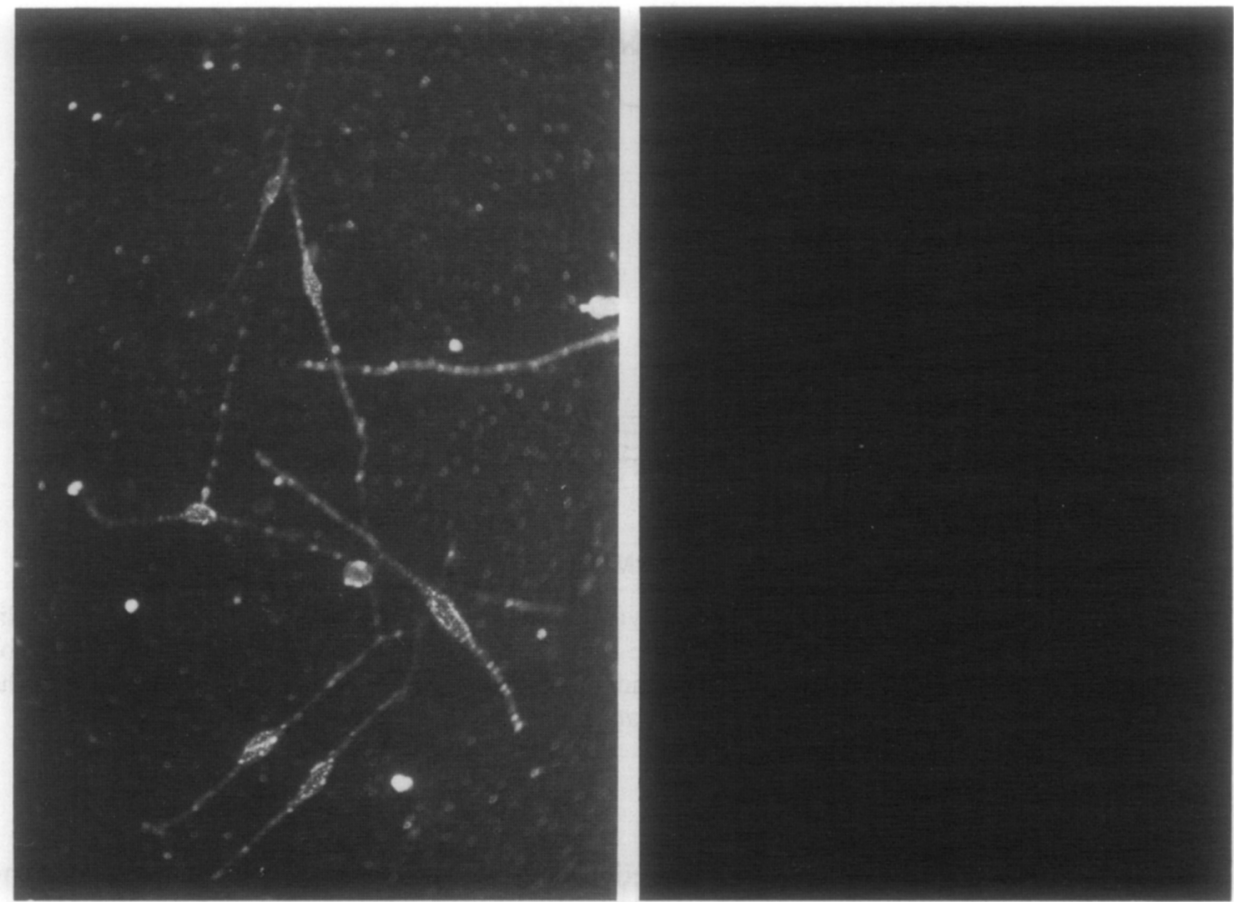

Fig. 4. Surface expression of extracellular matrix molecules by melanocytes. Cells were stained for indirect immunofluorescence in the viable state with anti-fibronectin (left-hand panel) or antithrombospondin (right-hand panel) $(210 \times)$.

tate was observed when anti-thrombospondin was used in place of anti-fibronectin (Fig. 3). The lack of detectable immunoprecipitate with the anti-thrombospondin antibody is not reflective of an inability of the antibody to precipitate thrombospondin from cell extracts since the same antibody effectively precipitates thrombospondin from extracts of epithelial cells when used under the exact conditions used here [2, 3]. By comparing radioactivity precipitated with antifibronectin with radioactivity precipitated by $10 \%$ trichloroacetic acid, we estimated that fibronectin accounted for approximately $0.3 \%$ of the total protein synthesized during the 4 -h incubation. When cell extracts were immunoprecipitated with anti-laminin and examined in the same manner, immunoreactive bands at 400 and $200 \mathrm{kDa}$ were seen (Fig. 3). The single broad band observed at the 200$\mathrm{kDa}$ locus may indicate that only one of the laminin $\mathrm{B}$ subunits is synthesized in significant quantities. Alternatively both $\mathrm{B} 1$ and $\mathrm{B} 2$ chains may be present. In certain experiments we were able to resolve the $200-\mathrm{kDa}$ component into two distinct bands (not shown). The presence of the $400-\mathrm{kDa}$ moiety in the extracts separated under reducing conditions suggests that melanocytic cells are capable of biosynthesizing the laminin A subunit. It is possible, however, that the band at the $400 \mathrm{kDa}$ locus represents a B hetero- or homodimer. Additional studies need to be done to distinguish these possibilities.

Melanocytes were next examined for expression of extracellular matrix mole- 


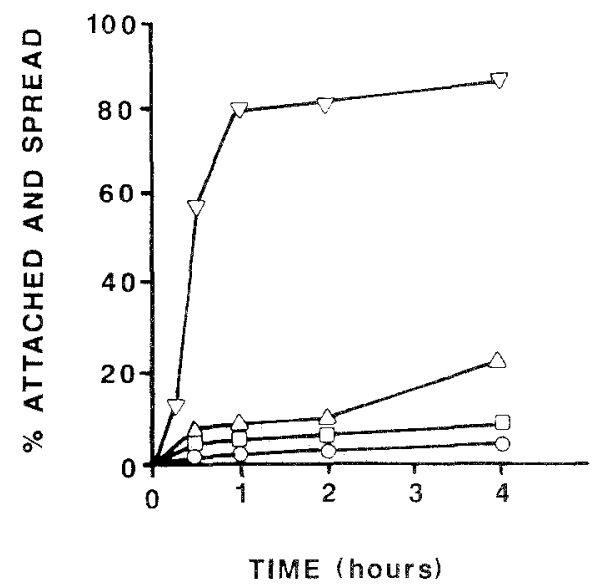

Fig.5. Attachment and spreading of melanocytes on fibronectin, 7 ), laminin $(\triangle)$, thrombospondin $(\square)$, or uncoated dishes (O). Values shown are average percentage attached and spread, based on duplicate samples in a single experiment. The individual values were within $10 \%$ of the average. The experiment was repeated three times with similar results.

cules on their surface. There appeared to be a direct relationship between the production of various extracellular matrix molecules and their expression at the cell surface. When melanocytes in the viable state were examined by indirect immunofluorescence, they showed distinct punctate staining with anti-fibronectin (Fig. 4). Punctate staining of intercellular material was also seen. In contrast, neither the cells nor the intercellular material showed staining when anti-thrombospondin or normal rabbit serum was substituted for anti-fibronectin (Fig. 4). When anti-laminin was used as the primary stain, distinct surface staining was seen. It was weaker than that seen with anti-fibronectin (not shown).

Melanocyte responses to extracellular matrix proteins. The effects of fibronectin, laminin, and thrombospondin on melanocyte adhesion and motility were examined. Wells of a 24-well dish were coated with $25 \mu \mathrm{g}$ of fibronection, laminin, or thrombospondin and examined for ability to support melanocyte adhesion. As shown in Fig. 5, melanocytes rapidly attached and spread on fibronectin-coated wells. The cells also attached and spread on laminin-coated wells although the response was much slower than on the fibronectin-coated wells (Fig. 5). In contrast, there was attachment but no spreading on wells caated with $25 \mu \mathrm{g}$ of thrombospondin or on uncoated wells (Fig. 5). Photographs showing cells on fibronectin-coated wells and on thrombospondin-coated wells $30 \mathrm{~min}$ after plating are shown in Fig. 6.

The agarose explant assay was used to assess melanocyte motility under unstimulated conditions and in the presence of fibronectin, laminin, and thrombospondin (Table 1). Fibronectin greatly stimulated motility while laminin was slightly stimulatory as compared to BSA alone. Thrombospondin did not stimulate melanocyte motility under the conditions used.

Effect of TGF- $\beta$ on melanocyte production of extracellular matrix proteins. 

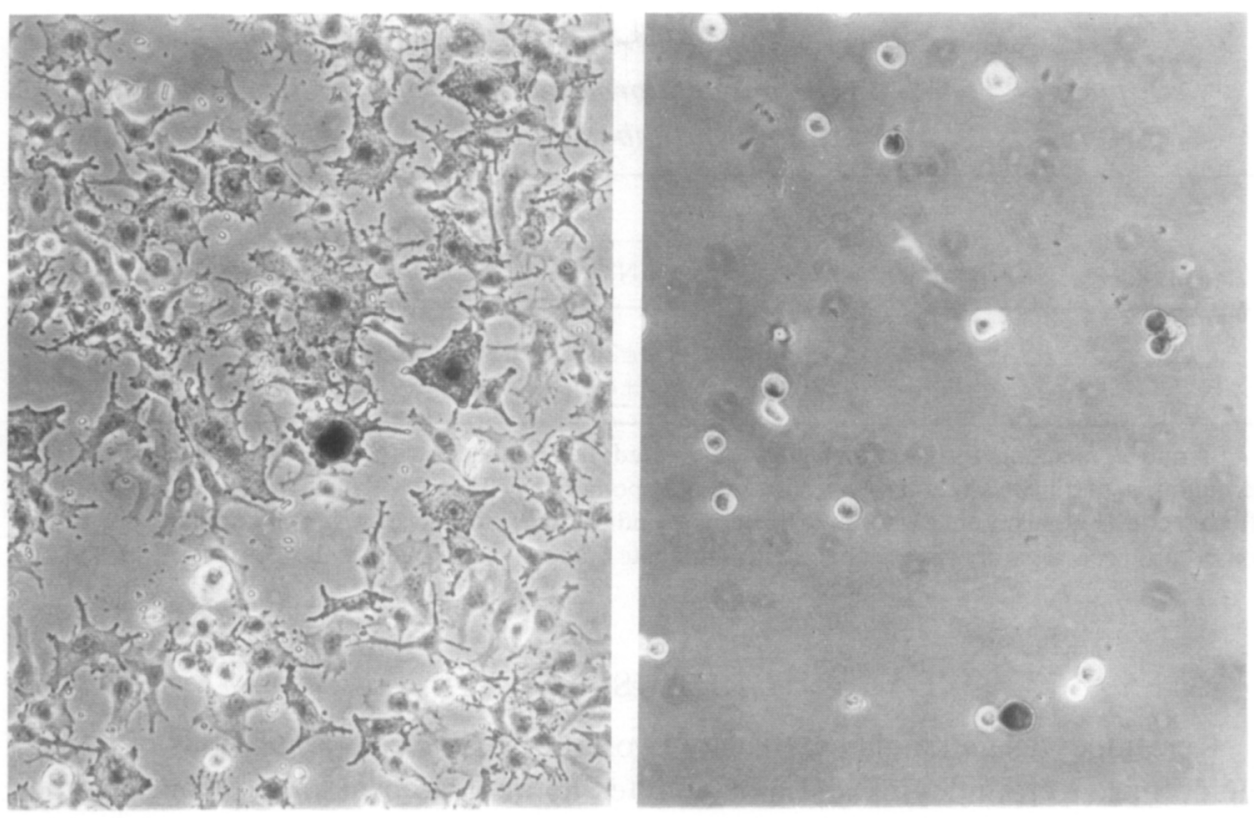

Fig. 6. Phase-contrast photomicrographs showing melanocytes on fibronectin (left-hand panel) or thrombospondin (right-hand panel), $30 \mathrm{~min}$ after plating $(168 \times)$.

TGF- $\beta$ is a potent stimulus for production of fibronectin by fibroblasts and epithelial cells [27-29]. To determined if fibronectin production by melanocytes could also be modulated, cells were treated for one day with $5 \mathrm{ng} / \mathrm{ml}$ of TGF- $\beta$ in KGM medium. Following this, the cells were washed twice and reincubated for an additional $2 \mathrm{~h}$ in KGM with or without TGF- $\beta$. At the end of the second incubation period, the culture fluid was collected and assayed for fibronectin by ELISA. As seen in Table 2, treatment of the melanocytes with TGF- $\beta$ stimulated fibronectin production. The same treatment had minimal effect on laminin and thrombospondin levels (Table 2).

\section{TABLE 1}

Effects of fibronectin, laminin, and thrombospodin on melanocyte migration

\begin{tabular}{|c|c|}
\hline Treatment ${ }^{a}$ & $\begin{array}{l}\text { Distance migrated } \\
(\mu \mathrm{m})^{b}\end{array}$ \\
\hline Untreated & $90 \pm 50$ \\
\hline Fibronectin-treated & $210 \pm 40$ \\
\hline Laminin-treated & $115 \pm 35$ \\
\hline Thrombospondin-treated & $75 \pm 40$ \\
\hline
\end{tabular}

\footnotetext{
${ }^{a}$ Motility was assessed using the aggrose drop explant assay. The overlay medium consisted of KGM supplemented with $200 \mu \mathrm{g} / \mathrm{ml}$ of BSA with or without $50 \mu \mathrm{g} / \mathrm{ml}$ of fibronectin, laminin, or thrombospondin. Migration was assessed after $18 \mathrm{~h}$.

${ }^{b}$ The values represent the average distances migrated \pm the standard deviations based on four replicates in a single experiment. The experiment was repeated two times with similar results.
} 
TABLE 2

Effects of TGF- $\beta$ on melanocyte production of fibronectin, larrivir, and thrombospondin

\begin{tabular}{llll}
\hline & \multicolumn{3}{c}{$\mathrm{ng} / \mathrm{ml} / \mathrm{l} \times 10^{6}$ cells } \\
\cline { 2 - 4 } Treatment $^{a}$ & FN & LN & TSP \\
\hline None & $350 \pm 20$ & $25 \pm 5$ & $<5$ \\
TGF- $\beta$ & $700 \pm 45$ & $30 \pm 7$ & $<5$ \\
\hline
\end{tabular}

a Control melanocytes and melanocytes treated for one day with TGF- $\beta$ were examined for production of fibronectin, laminin, or thrombospondin by ELISA. Values represent amounts of fibronectin (FN), laminin ( $I N$ ), and thrombospondin (TSP) produced in $2 \mathrm{~h} \pm$ standard deviations based on three separate experiments with duplicate samples per experiment.

\section{DISCUSSION}

Keratinocytes and melanocytes are two of the major cell populations of human epidermis. Keratinocytes and melanocytes lie in close proximity to one another and interact with each other in normal skin. Despite their locational similarities and interactions, keratinocytes and melanocytes are structurally, functionally, and embryologically distinct [6-7]. Keratinocytes are ectodermal derivatives which occupy a basilar position and interact with the basement membrane via hemidesmosomes. Each keratinocyte also has full desmosomal connections with adjacent keratinocytes. Basal keratinocytes are a rapidly dividing cell population. As these cells mature, cell division subsides and they migrate to the surface of the epidermis, become cornified, and eventually slough off. Melanocytes are of neural crest origin. These cells also occupy a basilar location but unlike keratinocytes do not have sub-basal adhesion plaques. Melanocytes do not form desmosomes and do not interact with other melanocytes. They interact with keratinocytes only through the tips of their dendritic processes. Unlike in keratinocytes, mitotic figures are rarely seen in melanocytes in normal skin. The cellular and molecular basis for their differences are not known.

It has been possible for some time to obtain large numbers of highly purified keratinocytes and to maintain these cells in culture for several passages [30, 31$]$. Using this approach, we have studied the production and utilization of extracellular matrix molecules by undifferentiated keratinocytes and by cells in various stages of differentiation. Our studies have shown that undifferentiated keratinocytes synthesize large amounts of thrombospondin [1]. The synthesized thrombospondin is secreted into the culture medium and bound to the cell surface. Our studies have also shown that keratinocytes utilize thrombospondin as an adhesion factor and that thrombospondin is more effective than laminin or fibronectin in promoting keratinocyte adhesion. It has been shown further that antibodies to thrombospondin inhibit keratinocyte adhesion under basal conditions [1] and that factors which induce differentiation concomitantly inhibit keratinocyte production of thrombospondin and cell-substrate adhesion [1,2]. Taken together 
with the observation that in vivo thrombospondin is localized to the dermal-epidermal junction [5], these data suggest that thrombospondin may be an important component of the keratinocyte extracellular matrix, mediating keratinocyte interaction with the basement membrane.

In the present study we have extended our earlier work by examining the production and utilization of extracellular matrix molecules by normal human melanocytes. Until recently, it was impossible to obtain large numbers of melanocytes in pure culture. We were able to obtain these cells by taking advantage of the recent finding that differential sensitivity to proteolytic enzymes combined with inclusion of TPA and cholera toxin in the culture medium could be used to separate melanocytes from keratinocytes and keep the melanocytes in a proliferative model for several passages in vitro [9]. The results of the present study indicate significant differences between melanocytes and keratinocytes in their production of extracellular matrix components. Specifically, melanocytes produce much smaller amounts of thrombospondin relative to other extracellular matrix components than do keratinocytes. Thrombospondin biosynthesis could not be detected using a $4-\mathrm{h}\left[{ }^{35} \mathrm{~S}\right]$ methionine incorporation protocol and thrombospondin could not be detected on the cell surface by immunofluorescence. We were able to detect traces of thrombospondin in the culture medium by ELISA (the most sensitive of the immunochemical methods used) but the amount detected was below the amount needed for accurate quantitation (approximately 1-5 ng). In contrast, melanocytes produced significant amounts of two other extracellular matrix molecules (i.e., fibronectin and laminin).

In addition to differences between keratinocytes and melanocytes in production of extracellular matrix molecules, the two cell types also differ in their ability to utilize these components as adhesion factors. Under the conditions of the assay, melanocytes did not attach and spread on thrombospondin (present study) while thrombospondin proved to be more effective as an adhesion factor than either fibronectin or laminin with keratinocytes [1]. In contrast to the effects of thrombospondin, fibronectin proved to be a potent adhesion factor for the melanocytes. The melanocytes also responded to laminin but the response was much less than with fibronectin. It is tempting to speculate that differences in the production and utilization of extracellular matrix molecules by melanocytes and keratinocytes contribute to the differences between these cells in their interaction with the basement membrane in vivo [6-8].

The melanocytes were also examined for response to the three extracellular matrix molecules in the motility assay. As in the adhesion assay, a good response to fibronectin was observed in the motility assay as well. In contrast, neither laminin nor thrombospondin was an effective stimulator of melanocyte motility. In this regard, the melanocyte response parallels that of keratinocytes. Recent studies by others [32-35] as well as our own [36] have shown that fibronectin is a potent stimulator of keratinocyte motility. In contrast, laminin not only does not stimulate keratinocyte motility but also has actually been shown to suppress the migration of these cells $[28,36]$.

The high level of melanocyte response to fibronectin and the lack of response 
to thrombospondin parallel the response of malignant melanoma cells to the same matrix components $[3,4]$. In contrast to what was observed in the present study with melanocytes, our previous studies with malignant melanoma cells showed that these cells were highly responsive to laminin [3, 4]. Whether increased responsiveness to laminin by melanoma cells relative to normal melanocytes contributes to malignant behavior of melanoma cells remains to be determined. Since neither the normal melanocytes nor the malignant melanoma cells appear to utilize thrombospondin as an adhesion factor, it may be that the increased response of the malignant cellls to laminin provides these cells with a mechanism for interacting with the basement membrane during invasion. An important role for laminin in melanoma cell-basement membrane interactions has been established in murine tumors [37]. Conversely, there are significant differences in the pattern of malignant spread between melanomas and squamous carcinomas. Squamous carcinomas tend to remain localized and spread by direct extension. They induce a large amount of local tissue destruction but metastasize relatively late. In contrast, melanomas often spread to distant sites without demonstrating a significant amount of local invasion and local tissue destruction. It is possible that differences in production and utilizatoin of extracellular matrix components by these cells contribute to their differences in biological behavior.

In summary, the present study examined the production and utilization of extracellular matrix molecules by normal human melanocytes. These studies showed that melanocytes produce fibronectin and laminin in amounts comparable to the amounts produced by normal epidermal keratinocytes. In contrast to keratinocytes, which also synthesize significant quantities of thrombospondin $[1,2$, 26], melanocytes produce very small amounts of this protein. The pattern of extracellular matrix molecule utilization reflects the pattern of synthesis. That is, the melanocytes utilize fibronectin and laminin as adhesion factors but are nonresponsive to thrombospondin. It has already been shown [1-4] that thrombospondin is a potent adhesion factor for normal and malignant keratinocytes. The differences in extracellular matrix production and utilization may contribute to the differences between keratinocytes and melanocytes in their interactions with basement membranes in vivo.

This work was supported by Grant PDT-324 from the American Cancer Society and by Grant AM35390 from the USPHS.

\section{REFERENCES}

1. Varani, J., Nickoloff B. J., Riser, B. L., Mitra, R. A., O'Rourke, K., and Dixit, V. M. (1988) J. Clin. Invest. 81, 1537-1544.

2. Nickoloff, B. J., Riser, B. L., Mitra, R. S., Dixit, V. M, and Varani, J. (1988) J, Invest. Dermatol. 91, 213-218.

3. Varani, J., Dixit, V. M., Fligiel, S. E. G., McKeever, P. E., and Carey, T. E. (1986) Exp. Cell Res. 167, 376-390.

4. Varani, J, Carey, T. E., Fligiel, S. E. G., McKeever, P. E., and Dixit, V. (1987) Int J. Cuncer 39 , $397-403$.

5. Wight, T. N., Raugi, G. J., Mumby, S. M., and Bomstein, P. (1985) J. Histochem. Cytochem. 33 , $295-302$.

6. Frenk, E., and Schellhorn, J. P. (1969) Dermatologica 139, $271-277$. 
7. Tarnowski, W. M. (1970) J. Invest, Dermatol. 55, 265-268.

8. Moellmann, G. E., Kuklinska, E., Klaus, S. N., and Lerner, A. B. (1986) J. Invest. Dermatol. 87, 392. [Abstract].

9. Eisinger, M., and Marko, O. (1982) Proc. Natl. Acad. Sci. USA 79, 2015-2022.

10. Dixit, V. M., Grant, G. A., Santoro, S. A., and Frazier, W. A. (1984) J. Biol. Chem. 259, 10,100-10,105.

11. Dixit, V. M., Haverstick, D. M., O'Rourke, K. M., Hennessy, S. W., Grant, G. A., Santoro, S. A., and Frazier, W. A. (1985) Proc. Natl. Acad. Sci. USA 82, 3472-3476.

12. Dixit, V. M., Haverstick, D. M., O'Rourke, K. M., Hennessy, S. W., Grant, G. A., Santoro, S. A., and Frazier, W. A. (1985) Biochemistry 24, 4270-4278.

13. Galvin, N. J., Dixit, V. M., O'Rourke, K. M., Santoro, S. A., Grant, G. A., and Frazier, W. A. (1985) J. Cell Biol. 101, 1434-1441.

14. Timpl, R., Rohde, H., Rennard, S. I., Foidart, J. M., and Martin, G. R. (1979) J. Biol. Chem. 254, 9933-9937.

15. Varani, J., Lovett, E. J., McCoy, J. P., Shibata, S., Maddox, D. E., Goldstein, I. J., and Wicha, M. (1983) Amer. J. Pathol. 111, 27-34.

16. Ronnett, G. V., Knutson, V. P., Kohanski, R. A., Simpson, T. L., and Lane, M. D. (1984) J. Biol. Chem. 259, 4566-4575.

17. Ruddon, R. W., Hanson, C. A., and Addison, N. J. (1979) Proc. Natl. Acad. Sci. USA 76, 5143-5147.

18. Laemmli, U. K. (1970) Nature (London) 227, 680-685.

19. Varani, J., Orr, W, and Ward, P. A. (1978) Amer. J. Pathol. 90, 159-172.

20. Baenziger, N., Brodie, G., and Majerus, P. (1972) J. Biol. Chem. 247, 2723-2731.

21. McPherson, J., Sage, H., and Bornstein, P. (1981) J. Biol. Chem. 256, 11,330-11,336.

22. Mosher, D. F., Doyle, M. J., and Jaffe, E. A. (1982) J. Cell Biol. 93, 343-348.

23. Raugi, G. J., Mumby, S. M., Abbott-Brown, D., and Bornstein, P. (1982) J. Cell Biol. 95, 351-354.

24. Jaffe, E. A., Ruggiero, J. T., Leung, L. L. K., Doyle, M. J., McKeown-Longo, P. J., and Mosher, D. F. (1983) Proc. Natl. Acad. Sci. USA 80, 998-1001.

25. Sage, H., Farin, F. M., Striker, G. E., and Fisher, A. B. (1983) Biochemistry 22, 2148-2155.

26. Wikner, N. E., Dixit, M., Frazier, W. A., and Clark, R. A. F. (1987) J. Invest. Dermatol. 88, 207-211.

27. Ignotz, R. A. and Massague, J. (1986) J. Biol. Chem. 261, 4337-4345.

28. Nickoloff, B. J., Mitra, R. S., Riser, B. L., Dixit, V. M., and Varani, J. (1988) Amer. J. Pathol. 132, 543-551.

29. Chakrabarty, S., Tobon, A., Varani, J., and Brillain, M. G. (1988) Cancer Res. 98, 4059-4064.

30. Liu, S. C., and Karasek, M. (1978) J. Invest. Dermatol. 71, 157-162.

31. Boyce, S. T., and Ham, R. G. (1983) J. Invest. Dermatol. (Suppl.) 81, 33s-40s.

32. Clarke, R. A. F., Lanigan, J. M., Della Pelle, P., Manseau, E., Dvorals, H. F., and Colvin, R. B. (1982) J. Invest. Dermatol. 79, 264-269.

33. O'Keefe, E. J., Payne, R. E., Russell, N., and Woodley, D. T. (1985) J. Invest. Dermatol. 85, 125-130.

34. Woodley, D. T., O'Keefe, E. J., and Prunieras, M. (1986) J. Amer. Acad. Dermatol. 12, 420-433.

35. Kolata, G. (1987) J. Invest. Dermatol. 88, 527.

36. Bachman, P., O'Keefe, E. J., and Woodley, D. T. (1986) J. Invest. Dermatol. 87, 128. [Abstract]

37. Liotta, L. A., Guirguis, R., and Stracke, M. (1987) Pigment Cell Res. 1, 5-15.

Received May 18, 1988

Revised version received August 8, 1988 